\title{
HOW TO STOP DIGITALIZATION - AN E-GOVERNMENT PILOT PROJECT CASE STUDY
}

\author{
Birgit Schenk and Tobias Giesbrecht ${ }^{1}$
}

DOI: $10.24989 /$ ocg.v331.20

\begin{abstract}
Pilot projects are a means of learning whether the promises of an E-Government-innovation hold true. We analyze the case of an unsuccessful E-Government pilot projects for patterns of obstructive behaviour and their justifications. The identified patterns can serve as early warning signs for endangered pilot projects. Furthermore we use them to deduce recommendations for improving the innovation-readiness of public administrations.
\end{abstract}

Keywords: e-government, innovation project, early warning signs, pilot projects, public administration

\section{Introduction}

Innovation and change are fundamental to mastering the challenges such as demographic development and the need to be competitive [8]. This is a matter of fact for all organizations in business and public administration at all levels (federal to local) [23].Multilevel reforms and modernization initiatives (e.g. New Public Management) following comprehensive plans under new regulations have taken place or are still being initiated, but the extent of the changes and of the innovation doesn't on the whole meet expectations [16]. Persisting in keeping the status quo seems to be perceived as success within public administration even if it is obvious that competition and sustainability demand change and innovation. Most of the recent innovations are run under the heading of E-Government. Genuine innovations are risky and therefore the public administrative organization tries them out in pilot systems before rolling them out. While there is ample evidence of failed E-Government projects and reasons why they failed [13], there is a lack of studies on how to manage those sensitive pilot systems. As they are set up to explore the operational and organizational feasibility of an E-Government innovation [14], they rely much more on the constructive collaboration of all stakeholders. Thus, monitoring the behaviour of them can be the key to understanding where a pilot-project stands and what should be done. As always, most can be learned from failures. Therefore, in this paper we will analyze a failed E-Government pilot system and ask ourselves: How did the actors manage to stop the project? Or more specifically: Which patterns of obstructive behaviour can be identified and how far are they justified. Those patterns can then be used by practitioners as early warning signs for project failure in future pilot systems and open up the field for specific research on early warning signs for E-Government failure.

\footnotetext{
${ }^{1}$ University of Applied Sciences - HVF Ludwigsburg, Germany, schenk@hs-ludwigsburg.de, University of Zurich, Department of Informatics, Zurich, Switzerland, giesbrecht@ifi.uzh.ch
} 


\section{Background}

\subsection{Culture of Innovation and Innovation Projects in the public Sector}

Innovation is an act of creative destruction [21]. Thus it touches fundamental principles of public administration such as stability, security and the control of public interests [1]. These principles demand employees who are able and willing to cope with stable and inflexible structures, routine, regularity, with comparatively little change in their day-to-day working life and are therefore comfortable with regulations, avoidance of any uncertainty, high power distance etc. At the same time these principles encourage only compatible norms and a compliant organizational culture. Deal and Kennedy call this a process culture [2]. Employees of a process culture concentrate on how to do things correctly because they assume and fear that they will be attacked if they have done things incorrectly. It is a culture of no mistakes, major avoidance of uncertainty, distrust, subordination or conformity. This is the opposite to aspects such as curiosity, trial and error, responsibility, accountability or activities for continuous improvement, etc. that are significant and essential for a culture of innovation. A culture of innovation asks for open mindedness about how to do things and the adaptation of goals, the exchange of project members in accordance with the project phases and tasks, and for employees who are willing to stand out. Taking these facts into consideration it is obvious that there is a cultural clash: the culture of innovation clashes with the culture of public administration. Therefore it is natural for public administration to oppose any innovation.

There are two categories of opponents: the constructive and the destructive [6]. Constructive opponents realize that the innovation cannot be stopped and therefore they try to change the outcome. These changes can be positive, if the constructive opponent is integrated in the process of change and if his knowledge is used to improve the introduction and implementation of the innovation. Destructive opponents try to delay and slow down this innovation or to stop it completely. They disguise their opinions and actions. Their arguments vary all the time according to the circumstances and the situation.

Public officials can be seen as being averse to risks [9]. In the context of change the attitude behind this follows a simple structure. Public officials ask themselves: Are fundamental risks to be expected if I don't change my attitude? If not, they don't do anything anymore. If they answer the question with "YES", then the next question arises: Are there consequences to be expected if I change my attitude? If he doesn't think so, he tries not to cause conflicts and starts to seek and to assess information as well as planning his next steps based on this to avoid change. Pretending to act hides his attitude. If he expects consequences, he asks the next question: Is there any realistic hope of a better solution than the innovation being targeted? If he doesn't see one any better his actions go against the innovation to avoid or slow down its implementation. This is called defensive avoidance. If there is realistic hope he estimates the time he needs to obtain and to assess more information. If there is no time left, he panics and tries to make others responsible and accountable for the problems caused and he stops working on it. [10] What does this kind of behaviour mean for public administration?

Public administration is bound to keep to the principles of equal treatment (non-discrimination) and legal certainty. Valid laws and provisions, regulations and guidelines as well as the resulting tasks are deduced from these principles and result in a special organizational structure with fixed organizational processes. They are tailored to cope with daily work but not tailored to meet the requirements of innovation processes nor introductions nor implementation. Each employee knows his competences and responsibilities according to his hierarchical position and he is strictly bound 
to them even if he works on a project. Hierarchical and functional barriers are adhered to [24] and intensified according to Hormon's Accountability Paradox. This says that public officials are obliged to act in compliance with laws, edicts, and rules even if their attitude or opinion is different. According to Hormon the concept of responsibility is central to our ability to deal with contradictory motives and forces. Responsibility has more than one meaning: responsibility describes people as authors and personally responsible for their actions; accountability means that people are answerable to the higher authority for their actions; obligations are moral actions determined by external sources which set standards and principles. These generate conflicts e.g. public officials have to act according to their obligations and against their own attitudes and opinions. So they learn to ignore their own moral principles and are simply executors without personal accountability. Four pathologies are generated:

Passing the buck: They deny personal authorship or having sufficient authority and they deny resources to achieve the institution's goal.

Scapegoating: A person is blamed in order to protect an institution's complicity and its' members illusion of their collective innocence.

Atrophy and Individual Moral Agency: The officials pretend to be the victim and thus discourage the exercise of personal authorship and responsibility.

Avoidance of Individual Responsibility: The relaxation of standards to foster the illusion of the victims' innocence and to foster the lack of confrontation and candour necessary for instilling a sense of personal answerability.

\subsection{Early Warning signs for project failure in pilot projects}

An early warning sign (EWS) provides an indication of risks arising and pointing to related barriers, difficulties, and/or failures [11]. An EWS typically refers to perceivable symptoms rather than to (invisible) underlying causes [23]. For example, if an important stakeholder frequently excuses $\mathrm{him} /$ herself from meeting, this is a visible sign; the underlying cause may range from a conflict of interests to simply a lack of time. Symptoms can relate to (1) client or stakeholder, (2) project's goal, (3) meetings, (4) the team, (5) the task, (6) the project, (7) the project management, (8) communication, (9) the overall management, (10) the project portfolio, and (11) to the process [7].

As EWS are visible they provide an experienced manager with a tool to monitor activities and react early. Pilot projects by definition have a limited scope: their purpose is to test the operational feasibility $\left[^{6}\right]$ and thus uncover the precedents and effects of an innovation. Thus top management typically shows a "wait-and-see" attitude. This is in sharp contrast to the established project management knowledge that top management support is key to project success [27]. The less support responsible persons have, the more they have to rely on sensing EWS.

Applying EWS to pilot projects is by no means trivial for two reasons:

A) A pilot project can be characterized as an instrument to uncover problems in the operational feasibility [21]. Thus the appearance of some EWS may be a justified output, particularly when the actual innovation is being tested (i.e. the main part of the project) 
B) As the innovation is untested, crises are much more likely than in a routine IT-project and their causes may vary significantly.

Therefore, those EWS are most valuable for pilot projects that can be observed in the first 20 percent of the project duration (i.e. the typical project ramp-up phase). In this phase, risks relating to the social subsystem and the project management subsystem are more relevant than risks relating to the technical subsystem [23].

\section{Methodology}

This paper describes an interpretative case study [25] at the end of an action design research project [22]. The authors held leading roles in the research project based on the action design theory, but withdrew from the driving seat before starting the interpretative case study. In interpretative case studies researchers collect the interpretations of the main actors and interpret them. An interpretative case study was chosen, because we aimed to get an in-depth understanding of how actors made sense of their actions and what it meant for them.

Two of the authors plus one senior research assistant collected and coded data using two methods:

1. During the last six months of the project, they took notes during and after major project meetings and after critical incidents. They captured information on activities and opinions of major stakeholders of the project. As it was not clear during this time whether the pilot system would succeed or not, they focused on information that could shed light on the outcome of the project.

2. At the very end of the project they interviewed five project participants from the public administration resulting in five interviews. Those five interviews were recorded, transcribed and coded.

The resulting raw data was jointly interpreted by two of the authors and the senior research assistants in several group meetings.

\section{Results}

\subsection{Case Context}

From 2012-2015 the authors were engaged in an Action Design Research project together with a major German city. Building on prior research [17] [19] [20] [18] in several iterations, a software to support citizen advisory services was developed and tested [5] [4] The final system was well accepted by both the participating advisors and citizens [4]. Thus we were able to move on from the proof-of-value phase to the proof-of-use phase [14] It was decided to roll out the CAG (=Citizens Advice Giving) pilot system to several citizens' advice bureaux to test the operational and organizational feasibility. Important tasks in this phase were internal marketing, defining how to offer the service, setting up the technical and organizational service infrastructure, creating an appropriate incentive system and training advisors for their qualifications. At this stage the participating researchers handed over the overall responsibility for the project to the participating project city members (this hand-over had been planned from the beginning). The researchers remained as consultants and observers and giving technical support. After six months the pilot phase was terminated without ever having really been started. It was obvious to the observers that 
most of the city personnel obstructed the project, but due to a lack of hard data we can only speculate why this was the case. Laura ${ }^{2}$, the departmental head responsible, was not sufficiently qualified to lead the organizational change and was afraid that this would become obvious. The supporting senior project member, Martha, was a typical uncommitted follower who held back her commitment until it was clear that the endeavour was a success. Marc, the organizational change agent, was the only active supporter but he had been entrenched in a fight with Laura since she had replaced him as the departmental head. Sam, the divisional head, knew about this conflict and therefore insisted that Laura should lead the organizational change. And the technician Tom did not have sufficient time.

While we can only speculate on the underlying motives of the actors, we could collect and analyse data on their patterns of obstructive behaviour and their justifications.

\subsection{Patterns of obstructive behavior}

The fundamental strategy was to do nothing at all and to ignore the requirements for the innovation project. This tactical distinctive coping behavior is called defensive avoidance [ $\left.{ }^{2} 4\right]$ and can be observed in two action patterns: delaying actions and the denial of responsibility.

\section{A) Delaying actions}

In order to support the management of project scope, time and cost, working packages including time lines, quality requirements and resources were assigned to the project members. In regular jour fixe the achievement of the given tasks were discussed and checked. The arguments used by the project members to justify their inactivity can be categorized in the passive and active delaying actions:

Passive (hidden) delaying actions: They said e.g. "I had no time." (Linda) or "The beat is too fast. The time is too short so there is no way to establish the citizens' advice at short notice." (Linda) or they argue based on unspoken rules and regulations, as well as norms such as "Daily business comes first then project business."(Linda) The arguments end up with statements like "I tell them ... and then I focus on my job." (Marc). Using all this kind of statements the project members tried to convince us that they couldn't do anything at all. At the same time they denied being responsible for their inactivity and tried to justify it with the current circumstances.

Active delaying actions: If passive delaying actions were impossible because they were answerable to the higher authority for their actions (accountability), they actively delayed the tasks e.g. Laura gave the instruction to all of her citizens' advisors to document the reasons why citizens refused to be advised. Later she used the documentation to justify her inactivity instead of analyzing it to improve e.g. the marketing or the way in which the new service was offered. Another tactic was to involve related departments in fulfilling the task given e.g. with the statement "All marketing activities have to be authorized." (Martha) so that our marketing activities had to be stopped. In the following weeks she argued that she couldn't do anything at all because the department responsible didn't answer her emails or didn't call her back. So the citizens knew nothing about the new service offered when they came to the citizens' advice bureau to change their address in their passports.

\footnotetext{
${ }^{2}$ We use Pseudonyms for all involved persons.
} 


\section{B) Denial of responsibility:}

Personnel accountability was an underlying theme of all statements and actions which went along with the actions described. The public officials refused to be accountable. If they were asked about their actions or their non-actions, their justification showed the following patterns:

Outside observer: The public officials tried to distance themselves by using statements which would be used by outsiders e.g. "They let you go to the wall.” (Marc) or „I would say, because I was not project manager of this phase." (Marc).

Non-accountable-role: Statements expressed indirectly or directly like "I never did something like that because my team leader Mrs. XY is responsible for my new employees." or "I can't see me doing that." (Laura) were often used to justify the lack of commitment or knowledge. This was accompanied by an active or passive arrangement of non-accountability e.g. "My people are allowed to decide for themselves." (Laura). She passed the decision on to one of the employees without any information about the background, the current circumstances or the consequences.

Camouflage tactics: The project members refused to reveal documents etc. which allowed the transparency and traceability of actions. They strove to hide or to disguise their actions, decisions or instructions to their employees to achieve a maximum of intransparency and untraceability e.g. they told us that they had sent an email with all the necessary information to all of their employees, but they refused to reveal the email or to send it via $\mathrm{cc}$ to all the project members. Additionally they refused to let externals talk to their employees and they refused to talk about specific subjects with externals.

Hiding deep in the masses: This phenomenon was often used with statements like "The department decided" or in involving people or other departments which helped to hold the line. This behaviour was chosen to enable them to hide among or behind others.

The unknown third party/person: The last piece in the jigsaw of the denial tactics was the "unknown third party/person" who is not there but is still a part of the project. e.g. "The citizens don't want this." was a statement which was often used but nobody had asked "the citizen" about his/her wishes or opinions.

\subsection{Justification patterns}

The patterns of obstructive behaviour were justified by three major themes and can therefore be categorized by them.

Insisting on line authority: One characteristic in projects is interdisciplinary cooperation within one or several departments. The project leader normally is the person with the most experience in project management or one of the senior members. Project leaders are responsible for a seamless cooperation and collaboration within the project team, the achievement of the set targets etc. Therefore they have the obligation and the competences to give instructions and feedback, to supervise project work and decide about the next step, to change project members if necessary or to change the direction taken. Their competences are limited to the project so that they can't interfere with the line and staff organization. Considering our case study we observed that the given line organization was mirrored to organize the project work. This ended in a stalemate. The project member Laura, who was boss of the citizens' advice bureaux, was therefore the project leader 
during the pilot phase. The project member Marc, who had initiated the project, was only responsible for the IT-part of the innovation project. When it came to the question of marketing, Marc was not allowed to do anything, even if he noticed that something was going wrong and addressed it in the project team because Laura was project leader and refused to give him the competences whenever his work involved her department. Therefore, he withheld his commitment, keeping within the set boundaries and not offending Laura. He stated “... now I can't help anymore."

Another example was inefficient delegation. Mike, the young technician, was responsible for a working package without any information about the situation. After a while he said "... It took a long time to gather all the necessary bits and pieces about the circumstances. After about three months I finally knew that Anna (citizens' advisor in the department for foreigners) was not part of our department ... it was kind of prodding in a pea-souper."

Insufficient hand-over of responsibility: To keep projects going during project members' vacations, it is normal to have an interim project member or to pass tasks round within the project team. In our case study the missing team members assigned a member of the line organization to be the interim member. This was positive because they knew all about the daily business and the circumstances of the department. The negative side was the fact that they were not involved in the project and therefore had second-hand information which was actually little or no knowledge about the project, its requirements or its necessities. As soon as they had to substitute the project member the project was slowed down. They then argued that they had no, or only a little, information with statements like "This part - I've never seen that ... it is almost embarrassing" or in the case of disinterest they said "I can't say anything. I had no target."

Being "economic" - protection of resources: If working packages were assigned to the project members they would need resources to guarantee or to produce the expected results and therefore hit the desired target. The project members, which at the same time were departmental heads, tried to minimize or to avoid time, effort and costs. They did this to protect their own time and efforts (self-protection) and that of their departmental staff (protection of others). Doing this they often argued that their people were allowed to decide if they wanted to do the necessary tasks or not. This went along with statements like "... we attach a certain value to voluntary work." (Laura) Other statements were „We noticed that it takes too much time and effort to key in all the information needed for this target group." (Laura) or "... we do this without spending too much time or energy..." or "... we did it because you wanted us to do it." or "Then we did it because someone had to do it."

\section{Discussion}

Our study offers three contributions: 1 . We demonstrate to employees in the public administration how to best obstruct an E-Government project. 2. We identify early warning signs for EGovernment pilots and 3. We demonstrate the need for developing an appropriate culture and structures for E-Government pilots. We regard the first contribution as somewhat ironic and therefore concentrate on the latter ones.

Early warning signs: Obstructive behaviour and their justification can be observed and therefore are good candidates for early warning signs. Both patterns relating to delaying actions and denial of responsibility are related to particular traits of public administration: Public agencies are rule-based systems [4] and deliberate delays are far more accepted instruments than in the private sector, 
especially if there is no real stake (as in pilot projects). And public administrations lay more emphasis on a clear separation of responsibilities.

The same holds true for the justification: While commercial companies typically have economical discussions before the pilot start or after the pilot (when discussing the outcome), in the CAG-pilot economic discussion were made during the project. While networked decentralized organizational structures become increasingly common in the private sector [15], strict line management is still unquestioned in the public sector. Successful hand-over of responsibilities mainly relies on the good will of the actors involved.

Thus, to our knowledge, for the first time we have uncovered EWS for pilot projects that are specific to the public administration: Purposeful delays and denial of responsibilities justified by insisting on established organizational rules and spontaneous economic discussions.

What does this mean for responsible people? We propose two measures:

1. Before the actual pilot starts, the attitude of the stakeholders should be tested in a pre-pilot, e.g. using only a very small subset of the functionality. This instrument uses the provisional nature of pilot projects to establish transparency of their feasibility.

2. Responsible project managers should continuously screen pilot project stakeholders' behaviour for EWS. This can be done by adapting established management instruments for stakeholder analysis [25].

Appropriate pilot project culture and structures: If a public administration accepts the necessity for innovations (and piloting them) it should not only provide responsible project managers with instruments to detect and repair counter-productive behaviour but it should also improve the innovation-readiness of the whole administration. The most important (and difficult) aspect is the organizational culture. A pilot project requires a different "mode" of work with a different value system and different norms for acceptable behaviour: Distancing yourself and operating like a wheel in a large machinery is good for routine work because it guarantees égalité and predictability of legal decisions. However it is bad in pilot project when distance leads to denial of responsibility and ultimately prevents learning. Denial of responsibility is easy in pilot projects: The typical first question "Are fundamental risks to be expected if I don't change my attitude?" will most of the time lead to the answer "NO", because a pilot system is not daily work. Additionally public employees have already learned that their behaviour is likely to be accepted if they stick to given laws, rules and norms as well as set organizational boundaries and competences. The "NO" also implies that the innovation is slowed down or even stopped and the hidden goal for the public officials to prevent innovation is reached. If the first question does lead to a "YES" because of incentives and pressure from internal or external factors, then they start to slow down the working process by pretending to be active while using the characteristics of administrative organizational structures and culture which lead to the pathologies according to Hormons' Accountability Paradox.

Instead of applying operational pressure, we rather propose a "pilot project culture": This starts with the senior administrative officials (who typically are the pilot project sponsors). On the one hand, they should not promote a pilot project prematurely as a success and push it into operations; pilot projects are far too risky for that and they would loose credibility. On the other hand the openness of the outcome should not entice them to a wait-and-see attitude. Rather, they should insist that the 
participating actors take advantage of the opportunities to learn. Practiced in this manner, top management support is as much needed and beneficial as in other IT projects.

A pilot project culture only comes to life if it is practiced regularly. Thus organizations should prepare themselves for the infrequent larger pilots through more frequent smaller trials, e.g. piloting small improvements of IT tools or small organizational change. In those "micro-pilots" appropriate behaviour can be incentivized and inappropriate behaviour sanctioned. Our research contributes to establishing a pilot project culture by clearly identifying patterns of undesired behaviour and their justifications. We showed that they are deeply engrained in public administration and not peculiar to any specific E-Government project.

A pilot project culture requires the implementation of an appropriate project organization. All observed justifications for inappropriate behaviour boil down to a complete ignorance of project structures. Project structures clashed with the organizational hierarchical structures and are dominated by them to the point that actors stopped project progress by insisting on working within their traditional line of authority. The actors ignored the dynamic nature of project knowledge (in contrast to the static nature of operational knowledge) and thus the hand-over of responsibility did not work. And they ignored the fact that projects have their own budget by frequently questioning the operational economy of the project. Issues of IT-project management are well-known in research and practice. However, the complete lack of established project practice in public administration came as a surprise to us. Thus we call for further research on project practice in public organizations and propose to frame the above mentioned micro-pilots as projects. Thus project management (and work package management) skills can be learnt and embedded in a public organization.

\section{Conclusions and Limitations}

Pilot projects are a means of learning whether the promises of an E-Government-innovation hold true. Innovations are risky; learning is hard work and requires both sufficient prior knowledge and a sufficient learning capacity. In this paper we showed that in the case of the CAG-pilot the public administration was ill-prepared for the risks and the learning requirements of the pilot. This offered the opportunity to study obstructive behaviour that ultimately lead to the unsuccessful termination of the pilot. We propose to use the observed behavioural patterns and their justifications as early warning signs for E-Government pilot projects. We furthermore use the results to propose a pilot project culture and - as a means of implementing it - micro pilots to train behaviour and how to work in a pilot project context.

There are some limitations to our research. As in any interpretative case study, the observed case may not appropriately represent the public sector outside Germany or even inside Germany. This trade-off between deep insights vs. external validity is typical for case studies. As we find support in the literature for many foundational phenomena and as all three authors have extensive experience in prior E-Government pilot projects, we are optimistic that we do not only report on a singular case, but we do not have scientific means to prove that. A second limitation refers to the authors' role in the project. While on purpose the two active authors did not sit in the driving seat of the pilot project they may have framed the participants in the prior phases of the project in a way that heavily influenced the pilot projects outcome. This again is a trade-off between the deep insight that a researcher receives when he is personally involved with the project's actors and his or her neutrality when gathering, coding and interpreting data. Thus we call for further research on EGovernment pilot projects to validate our results and encourage researchers and practitioners to also 
report their failures. In this way, we can improve the way we use the valuable instrument of pilot projects in the public sector and thus improve the E-Government innovation uptake.

\section{References}

[1] ClAVER, E.; LlOPIS, J.; GASCóM, José L.; Molina, H., Conca, F. J.: Public Administration: From Bureaucratic culture to citizen-oriented culture. International Journal of Public Sector Management Vol. 12, Iss. 5, 455-464 (1999)

[2] DEAL, T.; KENNEDY, A.: Unternehmenserfolg durch Unternehmenskultur, Bonn, Bad Godesberg, Rentrop (1987)

[3] GIESBRECHT, T.; SCHENK, B.; SCHWABE, G: Empowering front office employees with counseling affordances. Transforming Government, Vol. 9 (4), Emerald Group Publishing Limited, p. 517ff. (2015)

[4] GIESBRECHT, T.; SCHENK, B.; SCHWABE, G.: Learning with affordances: The case of citizens' advice services. In: Twenty Second European Conference on Information Systems 2014-06-09 (2014)

[5] GIESBRECHT, T., SCHOLL, H. J.; SCHWABE, G.: Smart Advisors in the Front Office: Designing employee-Empowering and Citizen-centric services. Rev. Government Information Quarterly, 30(4), pp. 377-386 (2015)

[6] HAUSCHILDT, J.: Widerstand gegen Innovationen - destruktiv oder konstruktiv?, in: Zeitschrift für Betriebswirtschaft, Ergänzungsheft 2, 69, 1-21 (1999)

[7] HAVELKA, D., RAJKUMAR, T. M.: Using the troubled project recovery framework: problem recognition and decision to recover. E-Service Journal 5.1, 43-73 (2006)

[8] HILL, H.: Von Innovationsmanagement und Management der Unsicherheit zur Zukunftsfähigen Verwaltung. Verwaltung \& Management, 1/2007, 17. Jg.; 1-7 (2011).

[9] HINZ, E.: Neue Verwaltungssteuerung und Mitarbeiterführung. Kontextsteuerung zur leitbildgerechten und leistungssteigernden Komplettierung des Managementwandels in NPMSystemen. München, Meiring; 1. Auflage (2012)

[10] JANIS, I. L.; MANN, L.: Decision making: A psychological analysis of conflict, choice, and commitment. New York, NY, US: Free Press Decision making: A psychological analysis of conflict, choice, and commitment (1977)

[11] KAPPELMAN, L. A.; MCKEEMAN, R.; ZHAN, L.: Early Waring Signs of IT Project Failure: The Dominant Dozen. Information Systems Management; Fall 2006; 23,4; ABI/Inform Global, 31-36 (2006)

[12] PHILIP, T.: Early warning signs of failures in offshore outsourced software development projects at the team level, University of Zurich, Faculty of Economics, Dissertation (2013) 
[13] MERTENS, P.: Fehlschläge bei IT-Großprojekten der Öffentlichen Verwaltung-ein Beitrag zur Misserfolgsforschung in der Wirtschaftsinformatik. Multikonferenz Wirtschaftsinformatik. Vol. 2. (2008)

[14] NUNAMAKER Jr, J. F., et al.: The Last Research Mile: Achieving Both Rigor and Relevance in Information Systems Research. Journal of Management Information Systems 32.3; 10-47 (2015)

[15] RICHTER, A. (ed.): Vernetzte Organisation. Walter de Gruyter GmbH \& Co KG, München (2014)

[16] ROMZEK, B.: Dynamics of public sector accountability in an era of reform International Review of Administrative Sciences, SAGE Publications, London, Thousand Oaks, CA and New Delhi, Vol. 66, 21-44; (2000)

[17] SCHENK, B.; SCHWABE, G.: Design IT-gestützter kooperativer Bürger-Beratung. In: Multikonferenz Wirtschaftsinformatik MKWI 2010, Universitätsverlag Göttingen, 2010-02$23(2010)$

[18] SCHENK, B.; SCHWABE G.: Bürgerservices vor Ort. In: Schwabe (ed.): Bürgerservices: Grundlagen, Ausprägungen, Gestaltung, Potenziale. Edition Sigma, Berlin, 139 - 160 (2011)

[19] SCHWABE G.; BRETSCHER, C.; SCHENK, B.: Designing for light-weight collaboration: the case of interactive citizens' advisory services. In: DESRIST Conference, Springer Verlag, 2010-06-04, (2010)

[20] SCHWABE, G.; SCHENK, B.; BRETSCHER, C.: Enabling advisors and citizens through Citizens' Advice 2.0. In: 14th Annual Conference of the International Research Society for Public Management (IRSPM), 2010-04-07 (2010)

[21] SEIFERT, E. K.: Einführung. Joseph Alois Schumpeter: Zu Person und Werk in: Joseph A. Schumpeter: Kapitalismus, Sozialismus und Demokratie. Einführung. Von Eberhard K. Seifert, 7. erweiterte Auflage, Tübingen/Basel, 3-14 (1993)

[22] SEIN, M. K., et al.: Action Design Research, Management Information Systems Quarterly $35: 1(2011)$

[23] THOM, N.: Innovationsbereitschaft, Innovationsfähigkeit und Innovationswiderstand Erfahrungen aus dem Schweizer Umfeld, in : Hilgers, D./Schauer, R./Thom, N.(Hrsg.): Innovative Verwaltung. Innovationsmanagement als Instrument von Verwaltungsreformen. Internationales Forschungscolloquium „Public Management“ an der Johannes Kepler Universität Linz. Eine Dokumentation, Linz, Donau, 15-38 (2011)

[24] WALTER, A.: Das Unbehagen in der Verwaltung. Warum der öffentliche Dienst denkende Mitarbeiter braucht. Edition sigma, Berlin (2011)

[25] WALSHAM, G.: Interpretive vase studies in IS research. Nature and method. European Journal of Information Systems, 6, 69-90 (1995) 
[26] WARD, J.; DANIEL, E.: Benefits Management: Delivering Value from IS and IT Investments. John Wiley and Sons, 2010

[27] ZWIKAEL, O.: Top management involvement in project management. A cross country study of the software industry. International Journal of Managing Projects in Business. 1, 4, 498 (2008) 